\title{
Comparative Efficacy of Ceftriaxone Versus Penicillin in the Treatment of Children with Severe Community- Acquired Pneumonia (CAP)
}

\author{
Dr. Muhammad Waqas*, Dr. Iftikhar Ijaz, Dr. Abdul Rehman and Dr. Ubaidullah \\ Department of Pediatric Medicine unit 2, Lahore \\ *Corresponding author: Dr. Muhammad Waqas, Department of Pediatric Medicine unit 2 , Lahore
}

\begin{abstract}
ARTICLE INFO
Received: 幽 February 05, 2019

Published: 蔧 February 15, 2019

Citation: Dr. Muhammad Waqas, Dr. Iftikhar Ijaz, Dr. Abdul Rehman and Dr. Ubaidullah. Comparative Efficacy of Ceftriaxone Versus Penicillin in the Treatment of Children with Severe Community-Acquired Pneumonia (CAP). Biomed J Sci \& Tech Res 14(4)2019. BJSTR. MS.ID.002593.
\end{abstract}

Keywords: Children; Community-acquired pneumonia; Efficacy; Ceftriaxone; Penicillin

\section{ABSTRACT}

Objective: Pneumonia is one of the most common cause of childhood morbidity and mortality. Effective and resource compatible antimicrobial management is one of the fundamental aspects of the treatment of severe CAP. Narrow-spectrum antibiotics are recommended as the first-line agent for children hospitalized with severe CAP.

Study Design: Randomized control trial.

Place \& Duration: Department of Pediatric Medicine, King Edward Medical University and Affiliated Hospital, Lahore from June 12, 2017 to December 12, 2017. Patients and methods: All the patients inducted in the study were randomly divided into two groups by using computer generated random number table. One group named as Group-A was given intravenous ceftriaxone at dose of $75 \mathrm{mg} / \mathrm{kg} /$ day once daily for 10 days. Other group named as Group-B was given intravenous penicillin as per guidelines of WHO 2014. Other supportive care was given equally to all the patients as protocol of treatment. Patients were re-evaluated on 4th day of treatment with antibiotics and efficacy was noted as per operational definition.

Results: In this study efficacy of IV Ceftriaxone was significantly higher as compared to Penicillin in treating severe CAP children. i.e. $84.7 \%$ vs. $71.8 \%$, p-value $=0.04$.Conclusion:Ceftriaxoneis more efficacious than penicillin in the treatment of children with severe CAP.

\section{Introduction}

Pneumonia is inflammation of lung parenchyma. Communityacquired pneumonia (CAP) is defined clinically as the pneumonia in a previously healthy child due to a bacterial, viral or less commonly fungal infection which has been acquired outside hospital [1]. Incidence of Pneumonia is 10 folds higher in developing countries as compared to developed countries [2]. In the last decade, pneumonia mortality in children has fallen to approximately 1.3 million cases in 2011, with most deaths occurring in low income countries [3]. About $16 \%$ childhood mortality under 5 years age in the world is due to pneumonia [4]. Among the various causative agents Streptococcus pneumonia (27-44\%), mixed Streptococcus pneumonia and other infection (9-30\%), respiratory viruses in 20$45 \%$ while $H$. Influenza is now rare after vaccination. The diagnosis can be made on basis of clinical examination, chest x-ray and Total leukocyte count(TLC count) [5]. Bacterial pneumonia need adequate antibiotics treatment, but only one third of these children gets proper antibiotics [6]. According to the WHO guidelines, children of 2 month to 5 years diagnosed with severe CAP should be admitted in the hospital and immediate empiric intravenous antibiotic therapy should be administered. Patients of severe CAP put on inadequate initial therapy didn't improve and survival also remained low after secondary adjustment of antibiotic regimen [7].

In a study clinical efficacy at the end of therapy was $90.6 \%$ for amoxicillin-clavulanate and $88.9 \%$ for ceftriaxone [5]. No local clinical study is available regarding efficacy of ceftriaxone in comparison with penicillin in the treatment of children with severe 
community acquired pneumonia. With the emergence of antibiotic resistance, the morbidity and mortality due to community acquired pneumonia in young children is increasing. It can be reduced by early administration of appropriate antibiotic.

\section{Material and Methods}

The study design was randomized controlled trial. The site of the study was Department of Pediatric Medicine, King Edward Medical University and Affiliated Hospital, Lahore. The duration of study was from June 12, 2017 to December 12, 2017.Sample size of 340 patients (170 patients in each group) was calculated with $95 \%$ confidence interval. Patients were recruited using non probability consecutive sampling technique. After proper approval from the ethical review committee (ERC) patients of severe CAP meeting the inclusion and exclusion criteria were included in the study after proper informed consent from the parents. Severe CAP was defined respiratory rate more than 49 breaths per minute for age less than one year and more than 39 for age more than one year plus one of the following: sub-costal or intercostal recessions, stridor in a calm child, with no history of hospital admission in last 1 month. Inclusion criteria was patients of both genders from age 2 months to 5 years diagnosed with severe CAP.

Patients of severe CAP exposed to any investigational drug within 1 month prior to study entry or enrolled in a concurrent study that may confound results of this study, having a co-morbid conditions like congenital heart disease, Meningitis, Central nervous system abscess, Pericarditis, Endocarditis, Pleural effusion or Empyema, Pneumothorax, Lung abscess, Bronchopleural fistula or Necrotizing pneumonia, or having signs and symptoms of involvement of systems other than respiratory system were excluded from study. Chest x-ray, complete blood count and C-reactive proteins (CRP) was sent along with the base-line investigation of patients enrolled in study. Each patient was evaluated and relevant data according to the predesigned questionnaire was collected and documented. All the patients inducted were randomly divided into two groups by using computer generated random number table. One group named as Group-A was given intravenous ceftriaxone at dose of $75 \mathrm{mg} / \mathrm{kg} /$ day once daily for 10 days. Other group named as Group-B was given intravenous penicillin as per guidelines of WHO 2014 i.e. benzyl penicillin: 50,000 units per kg IV every 6 hourly after-testdose for 10 days.

Other supportive care (antipyretics, I/V fluids, oxygen inhalation, nebulization and chest physiotherapy) was given equally to all the patients as protocol of treatment. Patients were re-evaluated on 4th day of treatment with antibiotics and efficacy was noted. Efficacy was defined as normalization of respiratory rate for age: Age 2-12 months: <50 /min; Age 1-5 Years: <40/min, settlement of chest in-drawings and stridor. All the data were collected on a preformed proforma. Data was analyzed using SPSS version 25. Mean and standard deviation was calculated for quantitative variables like age, weight, respiratory rate on admission. Frequency and percentages was calculated for qualitative variables like gender and efficacy. Chi square test was used.

\section{Results}

Total 340 patients (170 patients in each group) were included in study. Mean age of patients in Group-A and Group-B was $30.58 \pm 16.85$ months and $30.43 \pm 18.00$ months respectively. In Group-A $88(51.8 \%)$ patients were male and $82(48.2 \%)$ were female while in Group-B 84(49.4\%) patients were male and $86(50.6 \%)$ were female. Mean weight of patients in Group-A and Group-B was $13.67 \pm 4.13 \mathrm{~kg}$ and $13.75 \pm 4.46 \mathrm{~kg}$ respectively. In Group-A 88(51.8\%) patients and in Group-B 91(53.5\%) patients were malnourished (Table 1). In Group-A efficacy of treatment was seen in $144(84.7 \%)$ patients while in Group-B efficacy was seen in $122(71.8 \%)$ patients. The difference was significant $(\mathrm{p}<0.05)$ and group-A showed more efficacy than group-B (Figure 1). Data was stratified for age and weight of children. Among patients in the age group 2-12 months efficacy was higher in Group-A but it was not statistically significant i.e. Group-A: $90.9 \%$ vs. Group-B: $86.8 \%$, p-value $=0.0495$. However for patients who were in the age group 13-60 months; among them efficacy of treatment was higher in Group-A as compared to Group-B, Group-A: $90.5 \%$ vs. Group-B: $67.4 \%$, p-value $=0.00001$. In patients having weight $3-10.0 \mathrm{~kg}$, efficacy was achieved in 32(94.1\%) patients in Group-A and 33(84.6\%) in Group-B ( $\mathrm{p}=0.049)$.

Table 1: Demographic detail of patients.

\begin{tabular}{|c|c|c|c|}
\hline & IV-Ceftriaxone & Penicillin & Overall \\
\hline $\mathbf{n}$ & 170 & 170 & 340 \\
\hline Age (months) & $30.58 \pm 16.85$ & $30.43 \pm 18.00$ & $30.51 \pm 17.4$ \\
\hline \multicolumn{4}{|l|}{ Gender } \\
\hline Male & $88(51.8 \%)$ & $84(49.4 \%)$ & $172(50.6 \%)$ \\
\hline Female & $82(48.2 \%)$ & $86(50.6 \%)$ & $168(49.4 \%)$ \\
\hline Weight (kg) & $13.67 \pm 4.13$ & $13.75 \pm 4.46$ & $13.71 \pm 4.29$ \\
\hline Malnutrition (yes) & $88(51.8 \%)$ & $91(53.5 \%)$ & $179(52.6 \%)$ \\
\hline Malnutrition (no) & $82(48.2 \%)$ & $79(46.5 \%)$ & $161(47.4 \%)$ \\
\hline
\end{tabular}




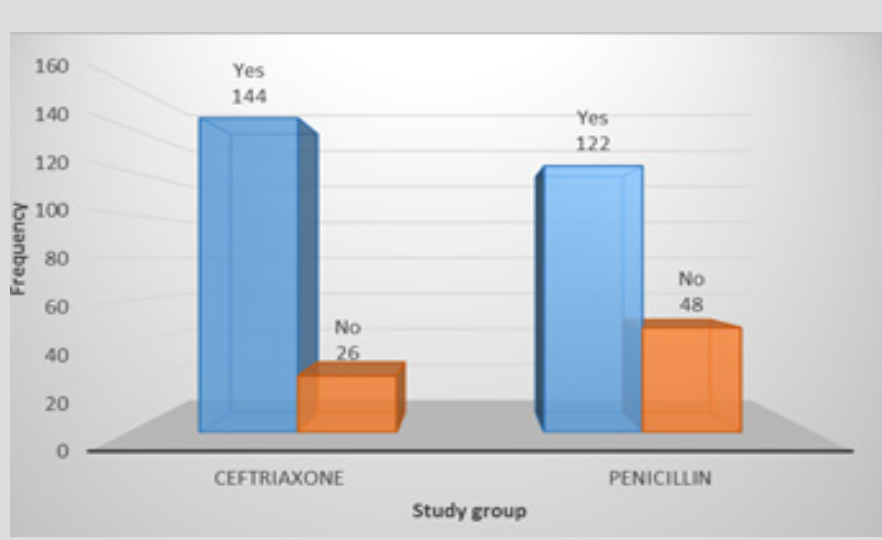

Figure 1: Comparison of efficacy in both groups ( $p$-value= 0.004$)$.

In $10.1-15.0 \mathrm{~kg}$ weighted patients, efficacy was achieved in $51(86.4 \%)$ patients in group A while in 38(66.7\%) patients in group B ( $\mathrm{p}=0.012)$. In 15.1-20.0kg weighted patients, efficacy was

Table 2: Efficacy of Treatment in relation to age of children.

\begin{tabular}{|c|c|c|c|c|}
\hline Age (Months) & Efficacy & IV-Ceftriaxone & Penicillin & p-value \\
\hline \multirow{2}{*}{$2-12$} & Yes & $28(90.9 \%)$ & $33(86.8 \%)$ & \multirow{2}{*}{0.0495} \\
\hline & No & $13(9.1 \%)$ & $5(13.2 \%)$ & \\
\hline \multirow{2}{*}{$13-60$} & Yes & $116(90.5 \%)$ & $89(67.4 \%)$ & \multirow{2}{*}{0.00001} \\
\hline & No & $13(9.5 \%)$ & $43(32.6 \%)$ & \\
\hline
\end{tabular}

Table 3: Efficacy of Treatment in relation to weight of children.

\begin{tabular}{|c|c|c|c|c|}
\hline Weight & Efficacy & IV-Ceftriaxone & Penicillin & p-value \\
\hline \multirow{2}{*}{$3.0-10.0$} & Yes & $22(94.1 \%)$ & $33(84.6 \%)$ & \multirow{2}{*}{0.049} \\
\cline { 2 - 4 } & No & $12(5.9 \%)$ & $6(15.4 \%)$ & $38(66.7 \%)$ \\
\multirow{2}{*}{$10.1-15.0$} & Yes & $51(86.4 \%)$ & $19(33.3 \%)$ & 0.012 \\
\cline { 2 - 4 } & No & $8(13.6 \%)$ & $51(68.9 \%)$ & \multirow{2}{*}{0.0003} \\
\cline { 2 - 4 } & Yes & $71(92.2 \%)$ & $23(31.1 \%)$ & \\
\hline
\end{tabular}

\section{Discussion}

Antibiotics are the mainstay in the treatment of CAP. Empirically used common antibiotics for CAP in children are cotrimoxazole, penicillins, macrolides, aminoglycosides and cephalosporins. One recent study suggested that floroquinolons specially levofloxacin can be effectively used in the treatment of CAP in children [8]. Due to its unique efficacy and safety ceftriaxone is widely used in the treatment of CAP worldwide. But resistant strain of Pneumococci $(6 \%)$ which is the most common organism causing CAP is noted worldwide [9]. In this study efficacy of IV Ceftriaxone was significantly higher as compared to Penicillin in treating CAP children i.e. $84.7 \%$ vs. $71.8 \%$, p-value $=0.04$. Evidence from Cetinkaya, et al. showed a combination of parenteral penicillin and chloramphenicol versus parenteral ceftriaxone to be equally efficacious in cure rates by day 10 (RR 1.05 ; 95\% CI 0.88 to 1.27 ) [10]. Results of this study is not in line with the findings reported by Cetinkaya et al as he had shown combination of parenteral achieved in $71(92.2 \%)$ patients in group A while in 51(68.9\%) patients in group B ( $\mathrm{p}=0.0003)$ (Tables 2 and 3). penicillin and chloramphenicol versus parenteral ceftriaxone to be equally efficacious.

In a clinical trial of amoxicillin clavulonic acid, ceftriaxone and penicillin, Karimeldin MA, et al. reported that total recovery was seen in $86 \%$ CAP patients on amoxicillin clavulonic acid , 90\% patients on ceftriaxone and 79\% patients on penicillin [5]. Roson $B$, reported after clinical trial that clinical efficacy at the end of therapy was $88.9 \%$ for ceftriaxone [11] Karimeldin MA, Roson B, in their studies have shown higher treatment efficacy for ceftriaxone which is in line with the results of this study. In 1 multicenter study, Ambroggio, compared beta-lactam monotherapy to beta-lactam plus macrolide [12]. In the sub-analysis of patients receiving betalactam monotherapy, $12 \%$ of the total cohort received an aminopenicillin with the remainder receiving a second-or third-generation cephalosporin. Re-admission rates were not statistically different between the 2 groups [12]. A single-center study by Newman et al., also demonstrated similar outcomes between patients treated with 
aminopenicillins and ceftriaxone [13]. Treatment failures were infrequent and not statistically different between the 2 groups. There exist many reasons to preferentially use penicillins as firstline antibiotic therapy for CAP. First, penicillins provide appropriate coverage for the most prominent pathogen, S pneumoniae [14].

Second, treatment of patients with non-central nervous system penicillin-resistant pneumococcal infections with penicillins has not been associated with treatment failures. These findings are consistent with in vitro data demonstrating bactericidal activity of penicillins at relatively low concentrations relative to the minimum inhibitory concentrations of pneumococcus $[15,16]$. The only cephalosporin that has been demonstrated superior to penicillin in S. pneumoniae eradication, even if resistant, is ceftriaxone [17]. No microbiologic failures have been reported for Streptococus pneumoniae with ceftriaxone at mean inhibitory concentration of $4.0 \mathrm{mg} / \mathrm{mL}$. 20 Thus, ceftriaxone or cefotaxime in standard doses is suggested by all guidelines as alternatives in case of first-line treatment failure, severe clinical condition, or not fully immunized children [18]. In a cluster randomized cross-over trial in adult patient with CAP efficacy of beta-lactam mono therapy was compared with beta-lactam- macrolide combination and fluoroquinolone monotherapy and it was found that empirical treatment with beta-lactam monotherapy was non-inferior to beta-lactam-macrolide combination or fluoroquinolone monotherapy [19]. In a study conducted at 114 centers in North America, Latin America, Europe and South Africa efficacy of oral solithromycin was compared with oral moxifloxacin and early clinical response was achieved in $78.2 \%$ patients with solithromycin compared to $77.9 \%$ patients with moxifloxacin [20]. A study conducted in 2007 showed that oral amoxicillin and intravenous penicillin $G$ are equally effective in the treatment of hospitalized children with non-severe CAP. However, amoxicillin is generally more cost-effective [21].

\section{Conclusion}

We can categorically assert from our study findings that ceftriaxoneis more efficacious than penicillin in the treatment of children with severe CAP.

\section{References}

1. Harris M, Clark J, Coote N, Fletcher P, Harnden A, et al. (2011) British Thoracic Society guidelines for the management of community acquired pneumonia in children: update 2011. Thorax 66(Suppl 2): 1-23.

2. Coates B, Camarda L, Goodman D, Kliegman R, Stanton B, et al. (2016) Nelson textbook of pediatrics. Philadelphia, Pa: Wilson.

3. Zar HJ, Madhi SA, Aston SJ, Gordon SB (2013) Pneumonia in low and middle income countries: progress and challenges. Thorax 68(11): 1052-1056.

4. (2016) World Health Organization. Pneumonia.

5. Salih KM, Bilal JA, Eldouch W, Abdin A (2016) Assessment of treatment of community acquired severe pneumonia by two different antibiotics. J Clin Diag Res 10(5): SC06-SC9.

6. (2018) World Health Organization. Consultative meeting to review evidence and research priorities in the management of acute respiratory infections (ARI). Geneva, USA.
7. Adrie C, Schwebel C, Garrouste Orgeas M, Vignoud L, Planquette B, et al. (2013) Initial use of one or two antibiotics for critically ill patients with community-acquired pneumonia: impact on survival and bacterial resistance. Crit Care 17(6): R265.

8. Bradley JS, Arguedas A, Blumer JL, Sáez Llorens X, Melkote R, et al. (2007) Comparative study of levofloxacin in the treatment of children with community-acquired pneumonia. Pediatr Infect Dis J 26(10): 868878.

9. Pallares R, Liñares J, Vadillo M, Cabellos C, Manresa F, et al. (1995) Resistance to penicillin and cephalosporin and mortality from severe pneumococcal pneumonia in Barcelona, Spain. N Engl J Med 333(8): 474-480.

10. Cetinkaya F, Gogremis A, Kutluk G (2004) Comparison of two antibiotic regimens in the empirical treatment of severe childhood pneumonia. Indian J Pediatr 71(11): 969-972.

11. Roson B, Carratala J, Tubau F, Dorca J, Linares J, et al. (2001) Usefulness of betalactam therapy for community-acquired pneumonia in the era of drug-resistant Streptococcus pneumoniae: a randomized study of amoxicillin-clavulanate and ceftriaxone. Microbial drug resistance (Larchmont, NY) 7(1): 85-96.

12. Ambroggio L, Tabb LP, Omeara T, Sheffler Collins S, McGowan KL, et al. (2012) Influence of antibiotic susceptibility patterns on empiric antibiotic prescribing for children hospitalized with communityacquired pneumonia. Pediatr Infect Dis J 31(4): 331-336.

13. Newman RE, Hedican EB, Herigon JC, Williams DD, Williams AR, et al. (2012) Impact of a guideline on management of children hospitalized with community-acquired pneumonia. Pediatrics 2012:peds. 20111533.

14. Queen MA, Myers AL, Hall M, Shah SS, Williams DJ, et al. (2014) Comparative effectiveness of empiric antibiotics for communityacquired pneumonia. Pediatrics 133(1): e23-e29.

15. Pérez Trallero E, Alkorta M, Giménez M, Vicente D, Aguilar L (2001) Prediction of in-vivo efficacy by in-vitro early bactericidal activity with oral $\beta$-lactams, in a dose-ranging immunocompetent mouse sepsis model, using strains of Streptococcus pneumoniae with decreasing susceptibilities to penicillin. J Chemother 13(2): 118-125.

16. Pérez Trallero E, Alkorta M, García Arenzana JM, Iturzaeta A, Gomariz M (1998) In-vitro, in-vivo and ex-vivo studies with oral beta-lactams against Streptococcus pneumoniae. J Antimicrob Chemother 41(6): 629634.

17. Harrison CJ, Woods C, Stout G, Martin B, Selvarangan R (2009) Susceptibilities of Haemophilus influenzae, Streptococcus pneumoniae, including serotype 19A, and Moraxella catarrhalis paediatric isolates from 2005 to 2007 to commonly used antibiotics. J Antimicrob Chemother 63(3): 511-519.

18. Pallares R, Capdevila O, Liñares J, Grau I, Onaga H, et al. (2002) The effect of cephalosporin resistance on mortality in adult patients with nonmeningeal systemic pneumococcal infections. Am J Med 113(2): 120-126.

19. Postma DF, van Werkhoven CH, van Elden LJR, Thijsen SFT, Hoepelman AIM, et al. (2015) Antibiotic Treatment Strategies for CommunityAcquired Pneumonia in Adults. N Engl J Med 372(14): 1312-1323.

20. Barrera CM, Mykietiuk A, Metev H, Nitu MF, Karimjee N, et al. (2016) Efficacy and safety of oral solithromycin versus oral moxifloxacin for treatment of community-acquired bacterial pneumonia: a global, doubleblind, multicentre, randomised, active-controlled, non-inferiority trial (SOLITAIRE-ORAL). Lancet Infect Dis 16(4) :421-430.

21. Atkinson M, Lakhanpaul M, Smyth A, Vyas H, Weston V, et al. (2007) Comparison of oral amoxicillin and intravenous benzyl penicillin for community acquired pneumonia in children (PIVOT trial): a multicentre pragmatic randomised controlled equivalence trial. Thorax 62(12): 1102-1106. 


\section{ISSN: 2574-1241}

DOI: 10.26717.BJSTR.2019.14.002593

Dr. Muhammad Waqas. Biomed J Sci \& Tech Res

(C) (i) This work is licensed under Creative

Submission Link: https://biomedres.us/submit-manuscript.php

$\begin{array}{ll}\text { BIOMEDICAL } & \text { Assets of Publishing with us } \\ \text { RESEARCHES } & \text { - Global archiving of articles } \\ \text { - Immediate, unrestricted online access }\end{array}$

